\title{
Escola Infanta D. Maria, Coimbra
}

\author{
E N T REVISTA CONDUZIDA POR CARLOS FOLHADELA SIM ÕES
}

Desta vez deslocámo-nos a Coimbra, à Escola Secundária Infanta D. Maria, para conhecermos as razões de uma Escola que se tem pautado pelos bons resultados obtidos em Química de acordo com os dados divulgados pelo Ministério da Educação. Acresce o facto de este ano ter sido a escola pública com melhores resultados globais. Foi também esta a Escola frequentada por Ana Pina, a recente vencedora de uma medalha de ouro nas Olimpíadas Ibero-americanas de Química, disputadas em Espanha. Conversámos com a Dr. ${ }^{a}$ Ana Luísa Baptista (AL), Presidente do Conselho Executivo, a Eng. ${ }^{a}$ Maria Eduarda Saraiva (MES), Professora de Química e a Dr. ${ }^{a}$ Teresa Almeida e Sousa (TAS), Coordenadora de Departamento. E como não podia deixar de ser, falámos ainda com Ana Pina (AP).
Dra. Ana Luísa, agradecia-lhe que nos apresentasse a Escola Secundária Infanta D. Maria

$A L$ - É uma Escola que tem cerca de 950 alunos repartidos pelo ensino diurno e nocturno. No nocturno, são alunos do ensino recorrente onde cerca de 30 frequentam já o "novo" recorrente. Normalmente o número atinge os mil alunos mas varia devido ao facto dos alunos do recorrente se poderem matricular ao longo do ano.

É uma Escola que ocupa este edifício desde 1948 embora as suas origens remontem a 1919 .

\section{Que cursos ministra?}

$\mathrm{AL}$ - Estamos virados essencialmente para a área das ciências, estudos científico-humanísticos embora os candidatos às humanidades sejam em muito menor número. O grosso das turmas é de ciências, temos uma turma de económico-sociais e duas de humanidades e na nova reforma temos o curso de ciências sociais e humanas.

\section{...e cursos tecnológicos?}

$A L$ - Neste momento não temos no ensino diurno. É difícil implementá-los. Este ano, foi-nos distribuído pela rede uma turma do curso tecnológico de acção social e não conseguimos alunos em número suficiente.
Alguma razão em especial?

$A L-E$ que os alunos que vêm para aqui são alunos interessados no prosseguimento de estudos.

São então alunos com objectivos definidos...

$A L$ - Sim, são alunos que têm claramente um objectivo. Normalmente virado para a área das ciências e daí termos 5 turmas no $10{ }^{\circ}$ ano, 6 no $11 .^{\circ}$ e 5 no $12 .^{\circ}$, nessa área.

A Escola está equipada para dar resposta a esses anseios?

$A L$ - A Escola tem na generalidade boas condições. Poderão existir escolas mais bem equipadas que a nossa, mas também as há bem piores. Considero que estamos razoavelmente bem.

Há alguma fórmula mágica que justifique o equilíbrio verificado ao longo dos anos no "ranking" divulgado pelo Ministério?

$A L$ - Não há fórmula nenhuma. Há, isso sim, um conjunto de factores que contribuem para isso...

...quais?...

$A L$ - Desde logo, alunos muito determinados que quando aqui chegam já trazem objectivos muito bem definidos, sabem o que querem e o que têm de fazer. Muitos pretendem ingressar em cursos ligados à saúde, e isso, como sabe, implica a obtenção de bons, muito bons, resultados. Necessariamente são alunos que vêm predispostos a trabalhar muito, o que se traduz na subida das médias.

\section{Os alunos são "escolhidos"?}

$A L$ - Não, de todo, temos é a felicidade de termos alunos assim. Os alunos, na grande maioria, são de um meio sóciocultural acima da média...

TAS - ...médio alto...

$\mathrm{AL}$ - ...o que juntamente com as condições da Escola, um corpo docente estável e empenhado contribuem para esses resultados. Não há mesmo nenhuma fórmula mágica...era bom!

Uma das áreas em que se destacam é a da química. Nos últimos resultados ocupam o $5 .^{\circ}$ lugar nacional com uma média muito próxima dos 15 valores. Que trabalho tem sido desenvolvido nos últimos anos, a nível de grupo disciplinar ou de departamento, que justifiquem os níveis alcançados e que tiveram também tradução em actividades extra-curriculares, como foi o caso da Ana nas olimpíadas de química?

MES - Vamo-nos reportar ao ano que terminou e em que leccionávamos o 12. ${ }^{\circ}$ ano de Química. Costumo dizer aos 
meus alunos, e repito aqui, que o professor é um facilitador de aprendizagens. Estas são feitas por eles. 0 professor ajuda-os a chegar onde pretendem. Cada um é que tem de definir as suas metas. Considero que todos os professores que leccionam $12 .{ }^{\circ}$ ano são professores do quadro de nomeação definitiva e com muitos anos de experiência, quase todos à beira da reforma...

\section{( ...gargalhada geral...)}

MES - ... e uma experiência de ter trabalhado com muitas gerações de jovens, o que em certa medida facilita o encontro dentro da sala de aula, o que considero de crucial importância...

Em jeito provocatório, a referência à reforma, poderá traduzir uma falta de crença nas novas gerações de professores ou admitem que os mais "novos" poderão dar continuidade ao vosso trabalho?

MES - Creio que as condições e a instabilidade que existem neste momento a um nível mais global, que aquele que é a pequena escola, que é uma peça pequena de uma engrenagem, não sei se serão suficientemente motivantes para os vindouros...

TAS - Posso acrescentar que este ano, os professores que aqui foram colocados são pessoas muito trabalhadoras, muito empenhadas, muito profissionais...

...o que não dá garantias de continuidade...

TAS - ...não, isso não temos. Estão cá este ano. No ano transacto estiveram quatro novos, este ano estão outros tantos...

$A L$ - Esta instabilidade, esta mudança permanente em que o professor não sabe onde vai ficar, os alunos não sabem se o professor os vai acompanhar no ano seguinte, a orgânica da própria escola a que as pessoas têm de se adaptar, são factores que muitas das vezes dificultam o trabalho. Por outro lado, e na Química, deve ser como nas outras coisas, os novos, desde que empenhados e dedicados, têm as mesmas possibilidades que os mais velhos.

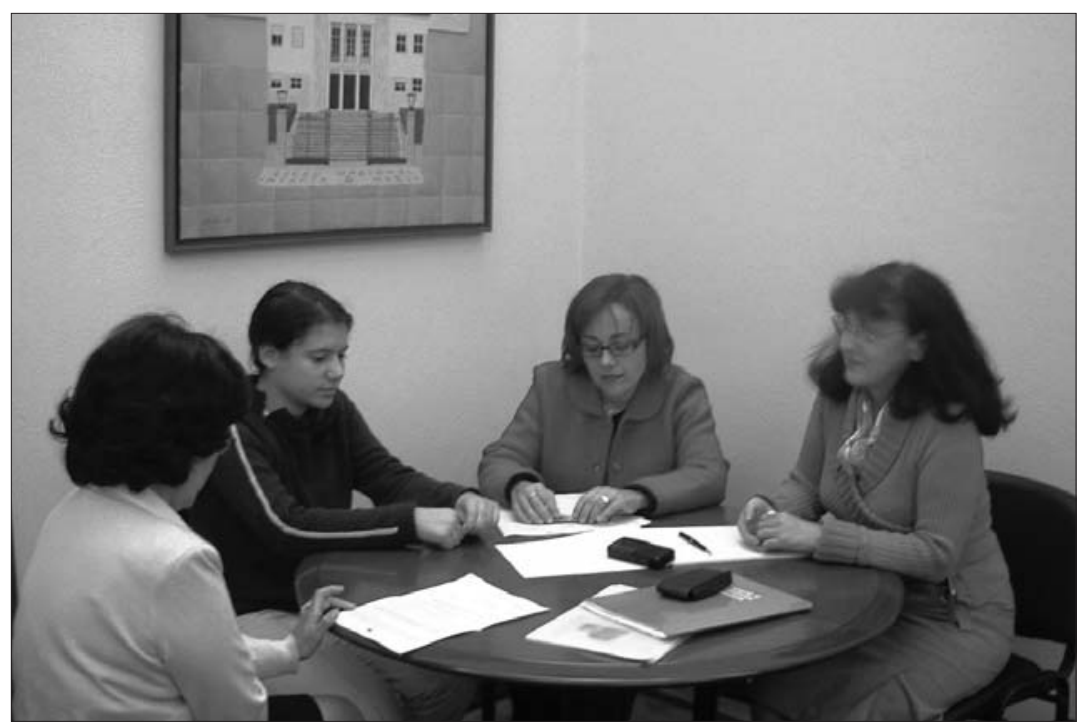

figura 1 As intervenientes, Dr ${ }^{a}$ Ana Luísa Baptista, Presidente do Conselho Executivo, a Eng ${ }^{a}$ Maria Eduarda Saraiva, Professora de Química e a Dra Teresa Almeida e Sousa, Coordenadora de Departamento e a aluna Ana Pina.

Falta-Ihes naturalmente experiência que considero fundamental. Há determinadas situações com que se tem de lidar na sala de aula o que me parece ser mais fácil para quem já tem mais experiência. Sabemos que as turmas, às vezes, também não são fáceis...

...claro, isso é imprevisível. Têm aqui, no âmbito da química, projectos implementados de forma sistemática?

TAS - A Professora Eduarda é a que tem trabalhado imenso no Laboratório de Química. Esteve muito tempo a dar as Quimicotecnias...

MES - ... os cursos tecnológicos de química...

TAS - o que originou que tivesse trabaIhado muito no laboratório. Mas assim um projecto...não.

Mas têm actividades extra-curriculares ligadas ao trabalho experimental que contribuam para a divulgação e fomento do interesse dos alunos por esta área?

MES - Não, como disse a Teresa, consegui dinamizar algumas actividades enquanto estive ligada aos cursos tecnológicos. Eram alunos especiais...diferentes..., no mundo humano da Escola e com esses alunos fazia-se um trabaIho diferente. Agora, os nossos alunos têm muitas actividades: explicações, desporto, etc.. Em Coimbra, os alunos têm muitas ofertas de actividades com- plementares fora dos portões da Escola...

...o que lhes retira muito tempo...

MES - ...claro, não Ihes dá tanto tempo para permanecerem na Escola. Têm muitas actividades proporcionadas pela família...

Como surgiu a participação nas Olimpíadas?

MES - A participação nas Olimpíadas surge, primeiro, porque soubemos da sua existência em informações transmitidas pela Coordenadora. Depois, como tinha um conjunto de alunos no $12 .^{\circ}$ que eram... "aquele aluno que é chato"...e temos um programa para cumprir o que deve impor determinado ritmo...

...alunos preocupados com os exames...

MES - ... não, alunos que exigem explicações, que obrigariam o professor a desviar-se da estrutura normal da aula, que tem de seguir para cumprir os programas. E concretamente a Ana Pina era uma miúda com perguntas diárias e constantes. O que levava a que as conversas tivessem que ocorrer nos intervalos. Então, lancei o desafio à turma dando-lhes conhecimento de todos os projectos que me chegavam às mãos. Há ou não resposta da vossa parte? E houve um conjunto de alunos que se interessaram. E como a Ana diz, até nem 


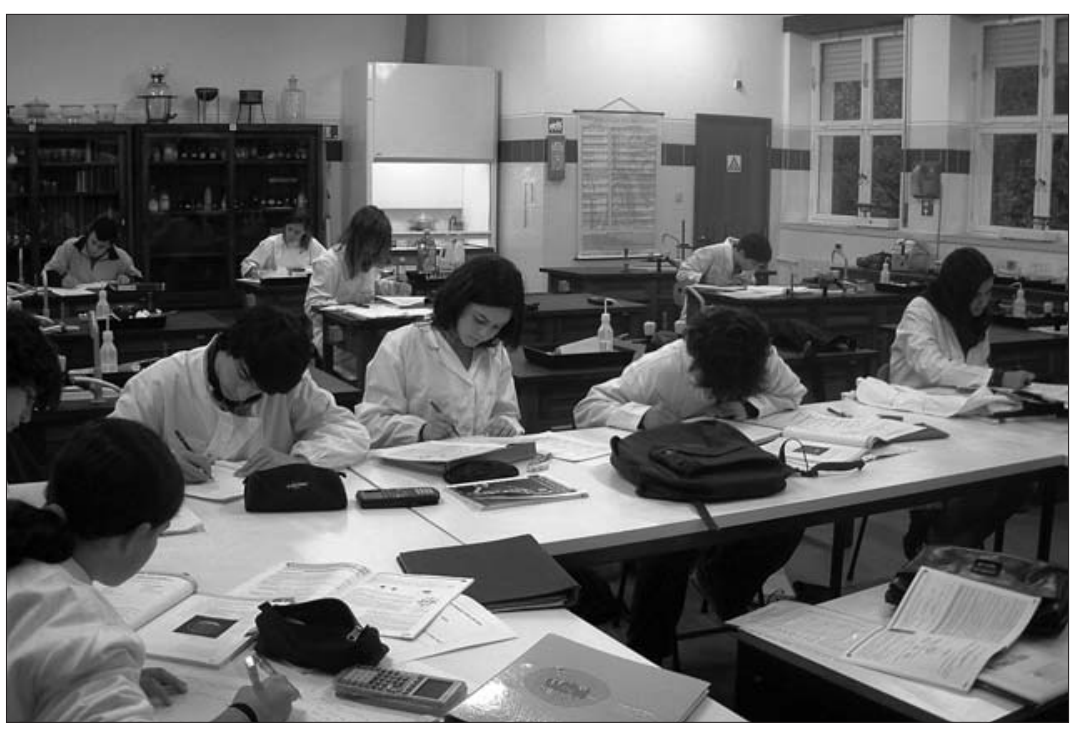

figura 2 Vista geral de uma aula prática.

tinha nenhuma preferência especial pela Química, gostava de todas as disciplinas. Tinha ainda outros alunos que conseguiram os mesmos níveis que ela nos exames. No entanto, ela tinha motivação acrescida por estar habituada a participar em muitas actividades complementares. Outros, que também atingiram o 20, limitavam-se ao estudo curricular.

Foi a primeira participação?

TAS - Não, não. Na Química já não participávamos há cerca de dez anos.

E agora com estes resultados?

MES - Não sei, eu lecciono o $12 .^{\circ}$. Não sei se outros colegas que leccionam $10 .^{\circ}$ e $11 .^{\circ}$ pretendem lançar o desafio aos alunos.

...e como Coordenadora?

TAS - Pois, vou divulgar. Este ano surgiu o anúncio, divulguei e participámos...

...sim, mas vai tentar que a Escola marque presença em iniciativas desta índole. É importante que diversas entidades continuem a promover estas iniciativas?

TAS - Exactamente. Acho que sim. 0 que considero é que a Química, com estes novos programas em vigor ou a entrar, provocarão uma grande mudança na componente laboratorial. Quando havia Quimiotecnias ou as Técnicas Laboratoriais essa componente era bem mais acentuada. E estas iniciativas poderão contribuir para esse reforço.

( breve interrupção pela chegada da Ana...)

$\mathrm{AL}$ - ...a menina que ascendeu ao estrelato...

Ana, pela simples anuência a uma solicitação da sua Professora, de um momento para o outro, vê o seu rosto em revistas e na televisão. Qual a sensação de ter muita gente a olhar para si? AP - De satisfação, mas sobretudo saber que é o reconhecimento pelo trabalho que desenvolvi. É, para além disso, a tradução da ajuda que recebi da Escola e dos Professores que me ajudaram.

MES - Posso dizer que a Ana embora tivesse um bom percurso até vir para Coimbra, iniciou os estudos no Porto, tinha lacunas em determinados conteúdos, em virtude de não ter tido professor durante algum tempo. Daí resultou que pela primeira vez os tivesse estudado no 12. ${ }^{\circ}$ ano. O que implicou um esforço muito intenso. Isso permitiu-Ihe, aquando da primeira prova, já os ter adquirido e estar ao nível dos outros que com ela, digamos, estavam a competir. Mas foi essencialmente um esforço individual, feito quase sozinha, apenas com orientação..

Sentiu grandes diferenças entre a prova nacional (Aveiro) e a que reali- zou em Espanha (Olimpíadas Ibero-americanas)?

AP - Não muito grandes, mas sim, foi mais difícil.

E a forma como são abordadas as matérias? O modo como são colocadas as questões, como se de uma "história" se tratasse, gostaria de vê-las reflectidas na prática do dia-a-dia no ensino da química?

AP - Sim, seria muito interessante. Mas também acho que muitos conteúdos que são testados nas Olimpíadas Ibero-americanas eram "demais" para os alunos do secundário...

...nem fazem parte dos programas...

AP- Pois não. Eu já achei as nacionais com coisas que não sabia, então as Ibero-americanas...

Continua a acreditar, como já disse, que o seu sucesso se deve a tão grande percentagem de transpiração e que o esforço e sorte têm menor peso. Ou revê esses valores e considera deverem merecer maior peso o esforço, dedicação e empenho?

AP - ...risos...Aqui, na Química?

Não, globalmente...

AP - Acho que mantenho as proporções. Tenho tido sorte com as pessoas que tenho encontrado. Se outros tivessem tido também essa felicidade também poderiam ter o mesmo desempenho. É sempre preciso ter essa sorte. Oportunidades que tenho e que outros, porventura, não têm.

Essa sorte está dirigida? Tem nomes? Ou é pura casualidade?

AP - Não, de todo. Essa sorte relacionase com o sítio em que nasci, a família que tenho, as pessoas que encontrei, os professores que tive, as escolas onde andei...

...todas as condições que lhe foram proporcionadas...

AP - Sim, não tenho culpa de ter a família que tenho mas tenho muita sorte por a ter.

"Não devemos desperdiçar oportunidades". É uma frase sua. Uma jovem 
de 18 anos proferir essa afirmação, muitas vezes ignorada pelos adultos, que significado tem?

AP - Aproveito tudo o que me pareça ser bom. À mínima indicação procuro saber o que é preciso, para participar. Tenho isto sempre presente, não perder oportunidades.

Ou seja, recolha de dados, análise e decisão à posteriori...

$\mathrm{AP}-\operatorname{Sim} \ldots$

O que traduz zero de precipitação e muita consciência e muito tino...

AP - Sim, normalmente é o que procuro fazer.

Há muita gente assim?

$\mathrm{AL}$ - É também essa a sorte de quem a encontrou. A Ana nunca foi minha aluna nem é minha filha mas imagino que seja uma sorte muito grande para os Pais ter uma filha assim, para os professores ter uma aluna assim...Se caIhar não é ela que tem tanta sorte assim...Ela deve fazer parte integrante dessa sorte...

\section{Cultiva a sorte...}

$\mathrm{AL}$ - Claro, não quer dizer que não haja outros que não se esforcem muito, não tenham as mesmas oportunidades e que não consigam chegar ao mesmo patamar mas com certeza que tem muito a ver com os seus objectivos, com a forma de estar. A sorte é ela que a constrói, imagino eu...

Consideram que é de mais exemplos destes que Portugal precisa?

MES - Sim, sim...independentemente dos resultados, mas atendendo à postura e à disciplina; nós focalizamos a Ana, mas ela estava inserida numa turma de que todos os professores diziam que era uma daquelas turmas de excepção. Era bom, era gratificante trabalhar com eles.

As mudanças que estão a dar os primeiros passos, nomeadamente os novos programas de Ciências FísicoQuímicas e o de Química permitirão, na vossa opinião, caminhar nesse sentido?

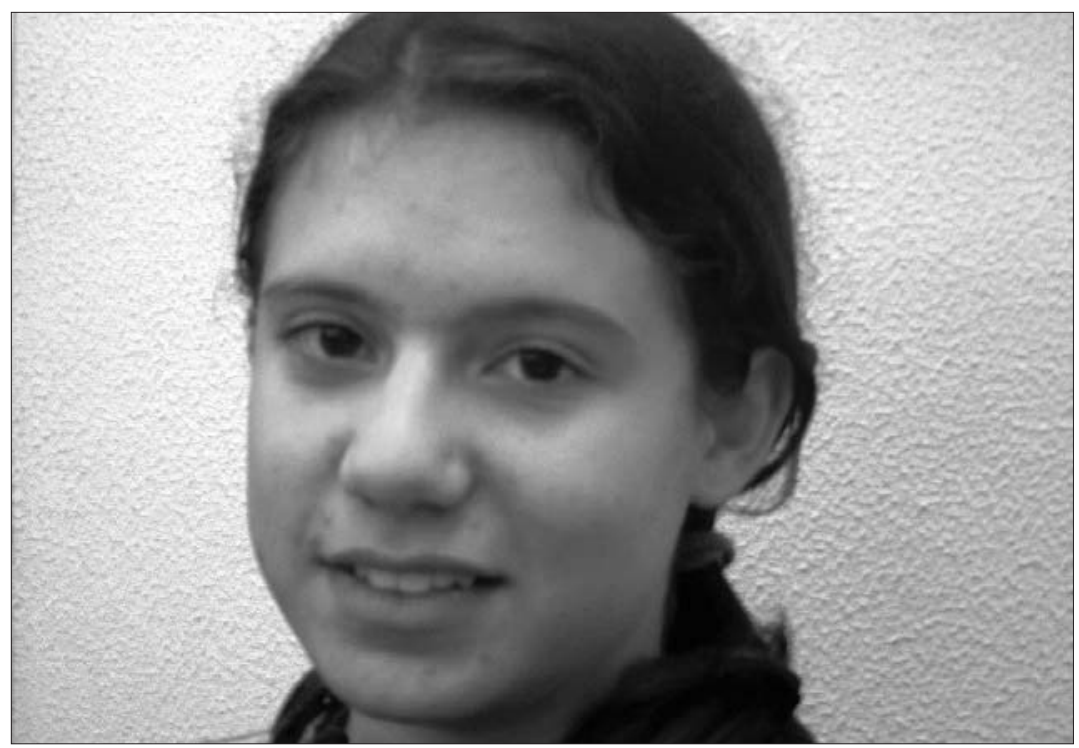

figura 3 Ana Pina.

TAS - Gostava de poder ter uma opinião mais abalizada. Estou a dar $10 .^{\circ}$ pela primeira vez. Mas considero que as aulas de Técnicas irão fazer muita falta...

...deveria ser reforçada a componente laboratorial...

TAS - ...dentro da Física e da Química. Fazem programas extensos partindo do princípio que a disciplina é de um ano e depois de certeza que a prática vai ficar para trás.

Já pensaram em soluções? Projectos, actividades...

TAS - Vai depender muito de quando o $10 .^{\circ}, 11 .^{\circ}$ e $12 .^{\circ}$ estiverem a funcionar na sua plenitude. Além de que, para o ano, também teremos $7 .{ }^{\circ}$ ano...

$A L$ - Há pelo menos essa indicação, isto é, a DREC já queria que tivéssemos este ano uma, duas ou três turmas desse nível de ensino. No entanto, entendemos que essa não seria a melhor solução, já que essa solução nos foi colocada tardiamente. Além de que a Escola que as perderia também disse que não. Este ano a proposta era facultativa.

Para o ano será obrigatória. E aí, teremos, como é evidente, um leque mais alargado de alunos com faixas etárias substancialmente diferentes.

Não retirará identidade à Escola? Não a descaracterizará?
AL - Penso que sim! Se por um lado os mais novos podem ser uma mais valia em determinados aspectos, não tenho grandes dúvidas de que irá descaracterizar aquilo que é típico de uma escola secundária. Isso sem dúvida. Basta dizer que neste momento os alunos entram aqui com idades entre os 15 e os 19 anos e passaremos a ter alunos de 12. São três anos com grande significado nestas idades. É uma diferença imensa.

Estão habituadas a que os alunos que aqui ingressam tenham objectivos muito bem definidos. Passar-se-á o mesmo com os do $7 . .^{\circ}$ ?

$\mathrm{AL}$ - Alguns saberão muito bem, mas a maioria não. Aliás aquilo que sabem não é o que irão querer depois. Há muitas mudanças...

TAS - Mas quando esta Escola tinha 7. ${ }^{\circ}$ ano, acho que havia alunos muito jeitosos era muito engraçado...

MES - ...e nessa altura apanhávamo-los desde mais novos e fazíamos o seu acompanhamento. Ficavam muito mais motivados para ir para o laboratório...

É vossa preocupação poder ver a vossa posição no ranking alterada?

AL - Não nos preocupamos minimamente com o rankings. Sabemos deles quando são publicados ou quando outras escolas nos fazem sentir isso ao longo do ano...hostilizando-nos um bocadinho...sei lá! Há, por vezes, uma 
certa rivalidade, como se seleccionássemos os alunos ou fizéssemos qualquer coisa de diferente. Mas não. Os alunos vêm para aqui porque querem. Ninguém os vai buscar ou manda embora...

Mas li algures, que há alunos que se vão embora no final do $1 .^{\circ}$ período porque não aguentam a "pedalada"...

$A L$ - Pois foi o que leu, mas foi o Sr. Jornalista que disse...Pôs na minha boca uma afirmação que não tive. Perguntoume se havia alunos a procurar a Escola. Respondi que sim, pela tradição de exigência, mas que também havia alguns que às vezes não aguentavam a pressão que sentiam. Nunca disse que procuravam escolas menos exigentes. Aliás, acho que não as há. Há sim, factores que fazem com que os resultados sejam estes. Há alunos que quando ficam numa turma muito boa ou não aguentam o ritmo de trabalho ou não têm os mesmos objectivos. E isso cria-Ihes uma maior pressão e acabam por sair. Aliás, o número de alunos que entram e saem no final do $1 .^{\circ}$ período não é significativo.

Há quem cá se matricule expressamente no $12 .^{\circ}$ ano?

AL- Poucos, embora alguns. Veja o caso da Ana que por contingências de ordem familiar veio para cá nessa altura.

Pois, a Ana frequentou o Luso-Francês no Porto...

$A P-\operatorname{Sim} . .$.

Mas quando chegou a Coimbra sabia para onde vinha ou veio para ao Infanta D. Maria por casualidade?

AP - Vim por recomendação....

Podemos saber quais?

AP - Recomendada por amigos dos meus Pais que disseram que a Escola era boa...

\section{Então algumas coisas se vão dizendo lá} fora...

AL - Mas lá fora diz-se. O que eu digo é que cá dentro não se diz, não se sente nem se pensa.
Que projectos para o futuro?

AP- Gostaria de ficar ligada à investigação

\section{Em Portugal?}

AP - Não acredito muito. O mais provável será no estrangeiro.

Não vislumbra uma luz ao fundo do túnel para poder fazer no seu país o que deseja?

AP - É difícil...os apoios e as hipóteses escasseiam.

O que considera dever ser feito pelos responsáveis que tutelam estas áreas de modo a inverter a situação?

AP - Várias coisas, como por exemplo, incentivar o investimento, apoiar os laboratórios associados, promover a investigação.

Poderemos esperar ver, num futuro próximo, o seu nome divulgado, por exemplo no Expresso, entre os jovens cientistas portugueses?

AP - Talvez mas preferia vê-lo na Nature...

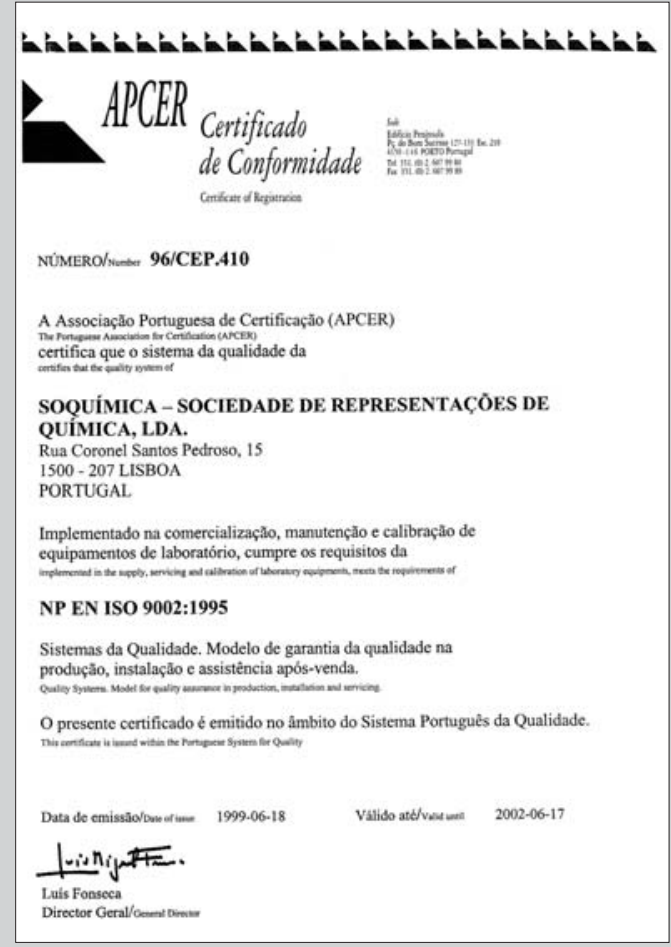



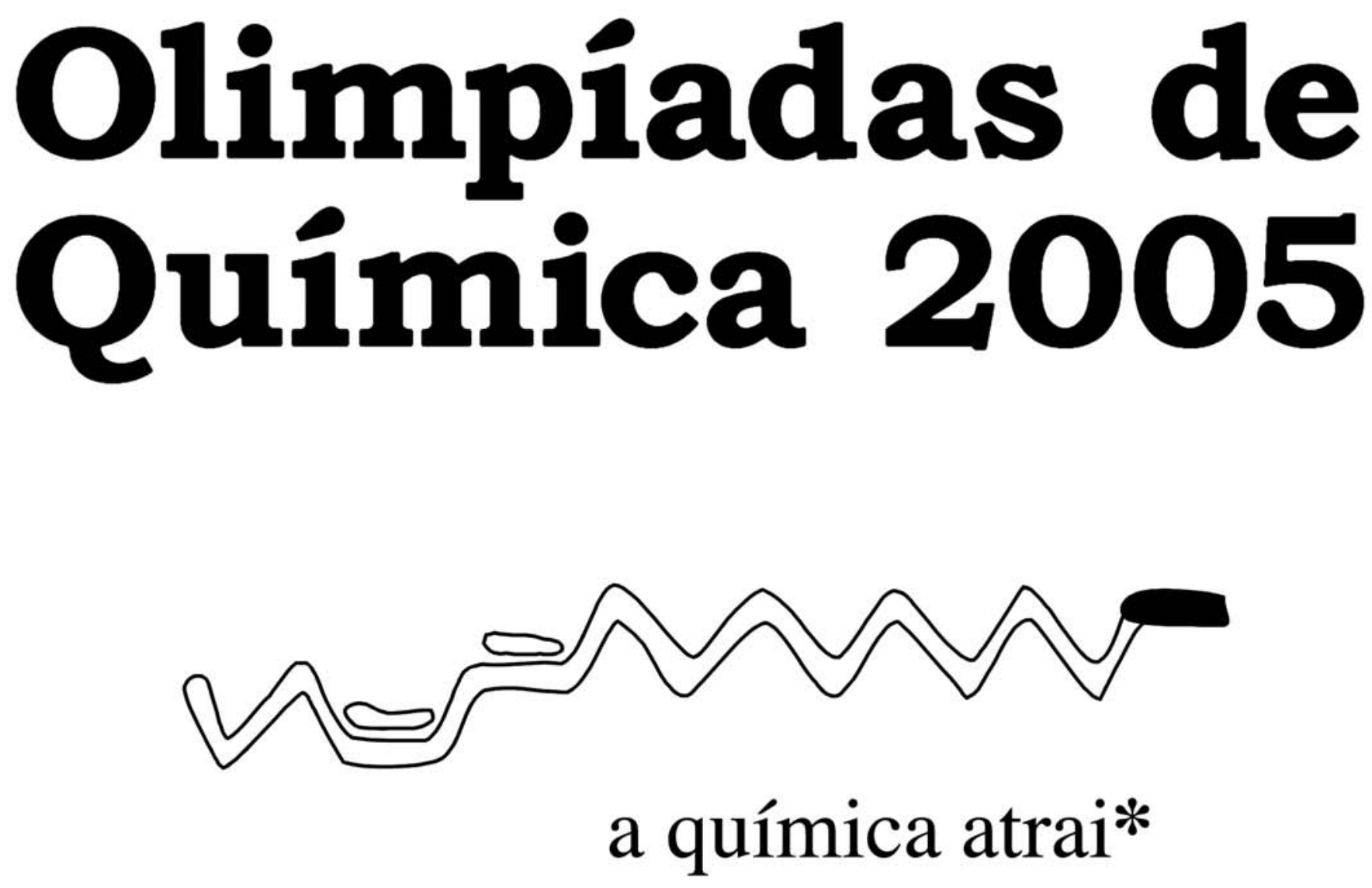

\section{Datas importantes}

31 de Janeiro de 2005

Limite da inscrição das equipas

na 2 a fase (semifinais)

26 de Fevereiro de 2005

Realização das Semifinais

7 de Maio de 2005

Realização da Final

Coordenador das Olimpíadas de Química: Paulo Ribeiro Claro

Departamento de Química, Universidade de Aveiro, P-381 0-193 AVEIRO olimpiadas@dq.ua.pt * Ver "Programa Atracção Química”, neste número. 